\title{
Preservation of Bioactive Compound via Microencapsulation
}

\author{
Fatin Hafizah Mohd Yusop ${ }^{1}$, Shareena Fairuz Abd. Manaf ${ }^{1}$, Fazlena Hamzah ${ }^{1}$ \\ ${ }^{I}$ Department of Chemical Engineering, Faculty of Chemical Engineering, University of Technology Mara, 40450. Shah \\ Alam.Selangor. Article Info: Submitted on March 20, 2017, Accepted on June 20, 2017.
}

\begin{abstract}
The aim of this paper is to discuss on the preservation of bioactive compound by using microencapsulation techniques. Microencapsulation is a process of building a functional barrier between the core and wall material to prevent any chemical or physical reactions. Microencapsulation provides an important technique in various food, pharmaceutical industry and textile product because has the ability to improve shelf-life, oxidative stability, provide protection and controlled biological activity release of active agents. Microencapsulation of plant extract, essential oils, vegetable has been developed and commercialized by employing various method including freeze drying, coacervation, spray drying, in situ polymerization and melt-extrusion. The most commonly used techniques for microencapsulation of oils are by using spray drying and coacervation method. Microencapsulation methods have been developed in order to modify the efficiency based on several factors such as types of active agents, shell material used, generating particles with a variable range of sizes, shell thickness and permeability. With this work, an overview regarding efficient and applications of microencapsulation process will be presented.
\end{abstract}

Keywords: Microencapsulation; Bioactive compound; Spray drying; Coacervation.

\section{Introduction}

From the ancient times, vegetables, herbs and essential oils has been added to the different food, agriculture, pharmaceutical industries and beverages because of their natural, safe to consume by human. It shown that bioactive compounds that commonly found in herbs and plants can be used to treat health problem and ailments such as stomach aches, intestinal problems, kidney disease, liver and bladder problem due to the antimicrobial, antioxidant and anticarcinogeni properties of the herbs. Bioactive compounds or chemical compound in plants have an important functional group such as monoterpenes, sesquiterpenes, aromatics and oxygenated compounds includes aromatics, ketones, alcohols, aldehydes, phenols, sesquiterpene alcohol, esters, lactones, oxides and ethers. ${ }^{2}$ However, mostly bioactive compounds are very sensitive in many factors such as degradation, thermal stability and environmental factor. The effectiveness of natural antioxidants such as polyhenols is depending on the preserving of their stability. One of the potential methods on preserving of herbs properties is via encapsulation method.

Microencapsulation of bioactive molecules has been efficiently used in increasing of bioavailability of the drugs and nutrients. ${ }^{3}$ The microencapsulation strategy will preserve their physical stability during processing, storage and prevent from deleterious interaction with food matrix and the environment. ${ }^{4,5}$ Moreover, microencapsulation capable to increase bioactivity owning to their micrometer size range.
Microencapsulation is a new strategy that widely used in pharmaceutical, chemical, agricultural and food processing. Microcapsules formed a small particle with a size varies between 1 to $5000 \mu \mathrm{m}$ based on an active agent surrounded either by a natural or synthetic polymeric membrane. Microencapsulation is a process by which an active core material is encapsulated in a shell of limited permeability that will protect active core material from external environment until the right stimulus encountered. This technique allow liquid or solid such as drugs, proteins, hormones, fertilizers and other small particle encased in a uniform shell. The composition of the shell material may vary depending on the method used and can be form from natural type material such as starch, gelatin, modified starch and cellulose, acrylates and other synthetic polymers. Figure 1 shows the microencapsulation process.

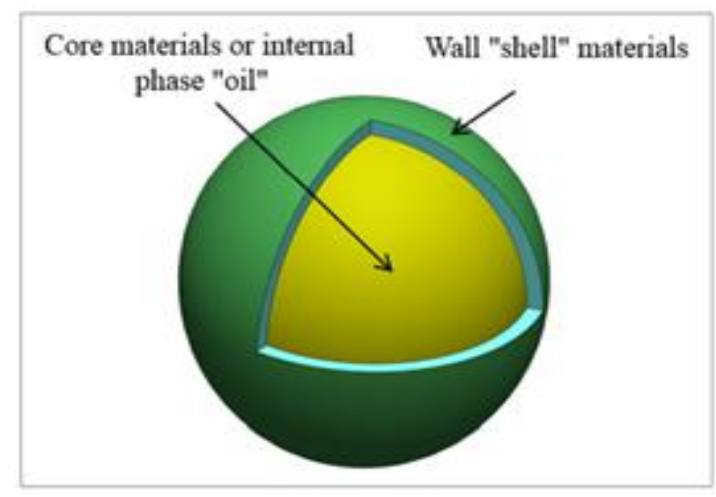

Figure 1: The core and wall material in microencapsulation. ${ }^{6}$ 


\section{Chemical Engineering Research Bulletin 19(2017) 50-56}

\section{Method of Microencapsulation}

Microencapsulation techniques can be archives via chemical and mechanical process or physical processes. The chemical process which an encapsulation method belongs is either or not the capsules are produced in a tank or reactor containing liquid, however in physical processes, which used a gas phase as a part of encapsulation method. The chemical and physical methods can be subdivided into physico-chemical and physico-mechanical techniques. ${ }^{7}$ Different techniques in microencapsulation processes with their relative particles size ranges is mentioned in Table 1. Furthermore, the most commonly used techniques for microencapsulation of oils are by using spray drying and coacervation method so in this section only described these two processes.

Table 1: Microencapsulation techniques with relative particle size ranges. ${ }^{7}$

\begin{tabular}{|c|c|}
\hline $\begin{array}{c}\text { Physico }- \text { Mechanical } \\
\text { Processes }\end{array}$ & $\begin{array}{c}\text { Physico }- \text { Chemical } \\
\text { Processes }\end{array}$ \\
\hline Spray drying & Coacervation \\
$(5-5000 \mu \mathrm{m})$ & $(2-1200 \mu \mathrm{m})$ \\
\hline Pan coating & Hot melt \\
$(600-5000 \mu \mathrm{m})$ & $(1-1000 \mu \mathrm{m})$ \\
\hline Co extrusion & Polymer - polymer \\
$(250-2500 \mu \mathrm{m})$ & incompatibility \\
& $(0.5-1000 \mu \mathrm{m})$ \\
\hline Fluidized bed & Solvent evaporation \\
$(20-1500 \mu \mathrm{m})$ & $(0.5-1000 \mu \mathrm{m})$ \\
\hline In situ polymerization & Encapsulation by \\
$(0.5-1100 \mu \mathrm{m})$ & Polyelectrolyte \\
& multilayer \\
& $(0.02-20 \mu \mathrm{m})$ \\
\hline Interfacial polymerization & Phase Inversion \\
$(0.5-1000 \mu \mathrm{m})$ & $(0.5-5.0 \mu \mathrm{m})$ \\
\hline
\end{tabular}

\section{Spray drying}

Spray-drying is the most popular physico-mechanical process that have versatile and low cost method to encapsulate fragrances, oils and flavors. ${ }^{8}$ This process can be described as a simple process that have similar operation as one stage drying that widely used in the industry for the production of a wide range of microspheres or microcapsules at high yield, good quality, low water activity, stable particles, easier handling and storage. ${ }^{9}$ The advantages for this spray drying making the process very suitable in the production of food and pharmaceutical industry. The size of the particles can be done generally around 5 micrometers with a large size distribution because of the variety of droplets sizes in the spray. More important, a successful microencapsulation must result in powder with minimum surface oil and maximum retention of the active material.

Spray drying technique allow the formation of particle from a dispersion of active compound in a solution of coating agent. ${ }^{10}$ It is a continuous transformation of feed from a fluid state into dried particulate form by mechanism of hot drying medium. Spray drying is very popular in the industry for the production microcapsules or microspheres based on the initial nature of the sprayed liquid that are suspension or emulsion. The liquid solution that contains the coating agent and active compound is transformed to form the dry micro-particle powders. Figure 2 show the illustration for spray drying process.

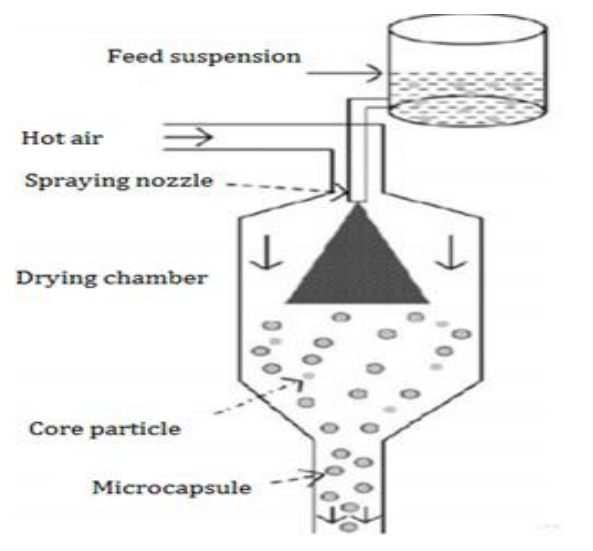

Figure 2: Illustrations of spray drying process. ${ }^{6}$

The microencapsulation process consists of the packing of particles by using suitable wall materials also known as encapsulating agents. Wall materials are very important to protect and extend microcapsule or microspheres functionality. The most common wall materials for encapsulation purpose are modified starch, gum arabic and maltodextrin. The core material for encapsulation is homogenized with the wall materials and then the mixture is fed into the spray dryer and atomized with a nozzle or spinning wheel. Water is evaporated by the hot air and contacted the atomized material and finally the capsules are formed and collected after they fall to the bottom of the drier. ${ }^{11}$

\section{Coacervation}

Coacervation method is the one of the oldest and most widely used for physico-chemical process. Coacervates also known as phase separation is formed between two oppositely charged biopolymers interact with each other by electrostatic attraction ${ }^{12}$ and this process occurs above narrow $\mathrm{pH}$ range. The Coacervation method mainly used in food industry. The bioplomers was produced by precipitate around a core of active ingredient, thus encapsulating it. The coacervation process can be classified into two methods that are 


\section{Chemical Engineering Research Bulletin 19(2017) 50-56}

simple and complex coacervation. The simple coacervation involved which one oppositely charged polymers whereby complex coacervation involved with one or more bioplomers. Simple coacervation is more cost saving and flexible operation compared to complex coacervation. The simple coacervation can use inexpensive inorganic salts but complex coacervation more sensitive to even a small $\mathrm{pH}$ change and also uses expensive hydrocolloids. The disadvantages of this method are difficulties to control particles size and to prevent particle agglomeration. Moreover, based on biopolymers material used made the particles only show limited stability in matrices.

\section{Encapsulation Materials}

The use of various techniques for microencapsulation is limited by the available number of wall materials that is good in water solubility at an acceptable level. ${ }^{8}$ Furthermore, the use of wall materials as encapsulating agents for the production of microcapsules can result in different physical properties that will depend based on the structure and the characteristics of each wall materials ${ }^{13}$ and different wall materials will result the change of functional properties of microcapsules. ${ }^{14}$ In other words, the emulsion characteristics such as the droplets size, stability, viscosity, as well as powder properties such as particle size, surface oil, the morphology and oxidative stability are affected by the type of wall materials used. ${ }^{15}$ There are various commercial approved encapsulating agents available to produce various microencapsulated foods as outlines in Table 2. Moreover, not all encapsulating agents are meet all the properties needed, so the modified encapsulating agents by combination with other coating materials such as oxygen scavengers, antioxidants, chelating agents and surfactant are required. ${ }^{16}$ The most popular encapsulation agents used in microencapsulation by spray drying are gum arabic, maltodextrin and chitosan. This is due to a high encapsulation efficiency of some oils extracted $(53 \%){ }^{17}$

Table 2: The approved food grade capsule wall material. ${ }^{17}$

\begin{tabular}{|c|c|c|}
\hline Polysaccharides & Fats and waxes & Proteins \\
\hline Gum Arabic & $\begin{array}{l}\text { Hydrogenated } \\
\text { vegetable oils }\end{array}$ & $\begin{array}{c}\text { Gelatins } \\
\text { (types A and } \\
\text { B) }\end{array}$ \\
\hline $\begin{array}{l}\text { Modified } \\
\text { Starches }\end{array}$ & Bees wax & $\begin{array}{l}\text { Whey } \\
\text { proteins }\end{array}$ \\
\hline Maltodextrins & Soy proteins & $\begin{array}{l}\text { Sodium } \\
\text { caseinates }\end{array}$ \\
\hline \multicolumn{3}{|l|}{ Alginates } \\
\hline Pectin & & \\
\hline Carrageenan & & \\
\hline
\end{tabular}

Gum Arabic is one of the most common wall materials used in microencapsulation by spray drying. It has a good ability to absorb volatiles flavour from surrounding and this will make gum arabic a good wall material for flavour encapsulation. Gum arabic presents many desirable characteristics to be good encapsulating agents due to its low viscosity, high solubility and good emulsifying properties. Although it has many desirable characteristics due to expensive cost, the oscillation in supply it make researchers to such other alternatives wall materials that could replace or modified it. ${ }^{18}$

Maltodextrins is a hydrolyzed starch that is widely used in microencapsulation of food ingredients ${ }^{19}$, and enhances the flavors. ${ }^{20}$ Maltodextrins also can be used as the wall materials for phenolic encapsulations. It offer the advantages such as the best thermal defenders, low cost, low viscosity at high solid concentrations, have neutral taste and aroma and also good antioxidants defenders. It also can be essential to preserve the integrity of the anthocyanins during encapsulation process. ${ }^{21}$ Although, Maltodextrins have good benefits due to its low emulsifying capacity made it the biggest problem for microencapsulation process. So the modified maltodextrins such as the combination of maltodextrins with others active bioploymers such as gum arabic, modified starches, and proteins as wall materials will increases dramatically their microencapsulation process by spray drying method. ${ }^{22,}$ ${ }^{23}$ For example, the mixture of Maltodextrins (60\%) and gum arabic (40\%) has been used for encapsulation procyanidins from grape seeds. ${ }^{20}$ The ratio of core substance to wall material is $30: 70 \mathrm{w} / \mathrm{w}$ and the slurry concentration was $20 \% \mathrm{w} / \mathrm{v}$. The combination between maltodextrins with gum arabic make the encapsulation efficiency increased up to $88.84 \%$ and the procyanidin was not change during drying process. ${ }^{24}$ The most important element is the stability of the microencapsulation was improved by spray drying.

Chitosan has been widely used as a wall material for preparing microcapsules of various purposes basically in human medicine such as in delivering nutrients and drug. As an example, chitosan has been used as coating material for encapsulation of olive tree leaves extract (OLE) ${ }^{25}$ The microsphere that has been loaded with OLE into chitosan showed the influence of structural interaction between polyphenols present in this extract and the matrix polymers. ${ }^{25}$

\section{Microencapsulation of Plant Extract}

The use of plant extract in the pharmaceutical, food and cosmetics industries is quite common due to various benefits in phytochemical properties. In addition, mostly plant extract have biological activities that can be used in the preparation of pharmaceutical 


\section{Chemical Engineering Research Bulletin 19(2017) 50-56}

products and functional foods. ${ }^{26}$ The phytochemical properties of plant extract can be change due to their origin Some plant extract very useful in medicinal properties such an antioxidant, anti-microbial and fungal, anti- inflammatory activity and for avoiding free radicals applications. Table 3 show a list a set of applications of encapsulating agents loaded with plant extract and their advantages.

\section{Application of Microencapsulation}

In industrial applications, the main objectives for microencapsulation are to control the rate at which it leaves the microcapsule without isolate the core completely. Much area in the industry can be beneficiate from microencapsulation technologies. Figure 3 show the schematics diagram for microencapsulation application in various field.

\section{Agriculture}

Nowadays, the most important application of microencapsulated product is in the area of pesticides and herbicides. The sex attractant pheromones are the one of the method that can be reduce insect populations by disrupting their mating process. The process can be done by the small amount of speciesspecific pheromone are dispersed during mating season, hence it will raising the amount of pheromone to the point at which there where hides the pheromone plume release by female mate. ${ }^{27,28}$ Encapsulating agents such as gelatin, gum arabic and polyurea serve a efficiency delivery transport to deliver the pheromone by spraying the capsule dispersion. ${ }^{28}$ Furthermore, the encapsulation method can protect the pheromone from oxidation and light during the storage and release process.

\section{Pharmaceutical}

Pharmaceutical and biomedical for controlled or sustained drug delivery industry can be said one of the most major encapsulation process. ${ }^{29}$ In drug delivery process, the most important step to construct the right biodegradable polymers in microencapsulation that will permit the efficient control release delivery systems. Using microencapsulation process, it will control the rate, duration and distribution of active drug at optimum condition. Furthermore, with these systems, the micro-particles that is highly sensitive to specific biological environment will designed to delivered an active drug in a specific way and this can protect sensitive drug from drastic environment $(\mathrm{pH})$ and can also reduce the amount of drug that will inject or consumed for patient.

\section{Food Industry}

Nowadays, the awareness towards a healthier way of living has been a major talk for consumer. Maintaining health and avoiding illness by diet is a unique offering of innovative system, many of which are augmented with ingredients to promote health. However, by adding various ingredients to food product that used to improve nutritional value can change their taste, color, texture and aroma. Sometimes, ingredients can also react with components presents in food that may limit bioavailability, slowly degrade and loss their activity. Today, microencapsulation is used to boost yield, improve the quality, and provide various texture blending, appealing aroma release, taste and color. ${ }^{30,31}$ In addition, microencapsulation can simplify the food manufacturing by converting liquids to solid powder, reduce the cost of production using appropriate handling equipment. The microencapsulation process also can stabilize the shelf life of the active ingredients. 


\section{Chemical Engineering Research Bulletin 19(2017) 50-56}

Table 3: Applications of encapsulating agents with plant extract and their advantages in microencapsulate.

\begin{tabular}{|c|c|c|c|c|c|c|}
\hline $\begin{array}{l}\text { Encapsulated } \\
\text { plant extracts }\end{array}$ & Application & Size & $\begin{array}{l}\text { Encapsulating } \\
\text { agents }\end{array}$ & Method & Advantages & References \\
\hline $\begin{array}{l}\text { Origanum } \\
\text { vulgare }\end{array}$ & $\begin{array}{c}\text { Food } \\
\text { preservatives }\end{array}$ & $<10 \mu \mathrm{m}$ & Starch & $\begin{array}{l}\text { Supercritical } \\
\text { fluid }\end{array}$ & - & 32 \\
\hline Rosemary & - & $\begin{array}{c}12.1-13.5 \\
\mu \mathrm{m}\end{array}$ & $\begin{array}{c}\text { Gum Arabic, } \\
\text { maltodextrins } \\
\text { and modified } \\
\text { starch }\end{array}$ & $\begin{array}{l}\text { Sparay } \\
\text { drying }\end{array}$ & - & 33 \\
\hline Pimenta dioica & - & $\begin{array}{c}1172- \\
1224 \mu \mathrm{m}\end{array}$ & Chitosan & $\begin{array}{c}\text { Complex } \\
\text { coacervation }\end{array}$ & $\begin{array}{l}\text { Enhancement } \\
\text { of } \\
\text { antimicrobial } \\
\text { activity }\end{array}$ & 34 \\
\hline $\begin{array}{c}\text { Scihinus molle } \\
\text { REv L }\end{array}$ & Insecticidal & $0.2-40 \mu \mathrm{m}$ & $\begin{array}{c}\text { Maltodextrin } \\
\text { and gum arabic }\end{array}$ & Spray drying & $\begin{array}{c}\text { Prolonged } \\
\text { effect }\end{array}$ & 35 \\
\hline $\begin{array}{c}\text { Cymbopogom } \\
\text { spp }\end{array}$ & Antimicrobial & $10-250 \mu \mathrm{m}$ & Polyvinylalcohol & $\begin{array}{c}\text { Simple } \\
\text { coacervation }\end{array}$ & $\begin{array}{l}\text { Extended } \\
\text { release }\end{array}$ & 36 \\
\hline $\begin{array}{c}\text { Ocimum } \\
\text { sanctum Linn } \\
\text { spp }\end{array}$ & - & $392.3 \mu \mathrm{m}$ & Gelatin & $\begin{array}{c}\text { Simple } \\
\text { coacervation }\end{array}$ & $\begin{array}{c}\text { Stability } \\
\text { improvement }\end{array}$ & 37 \\
\hline
\end{tabular}

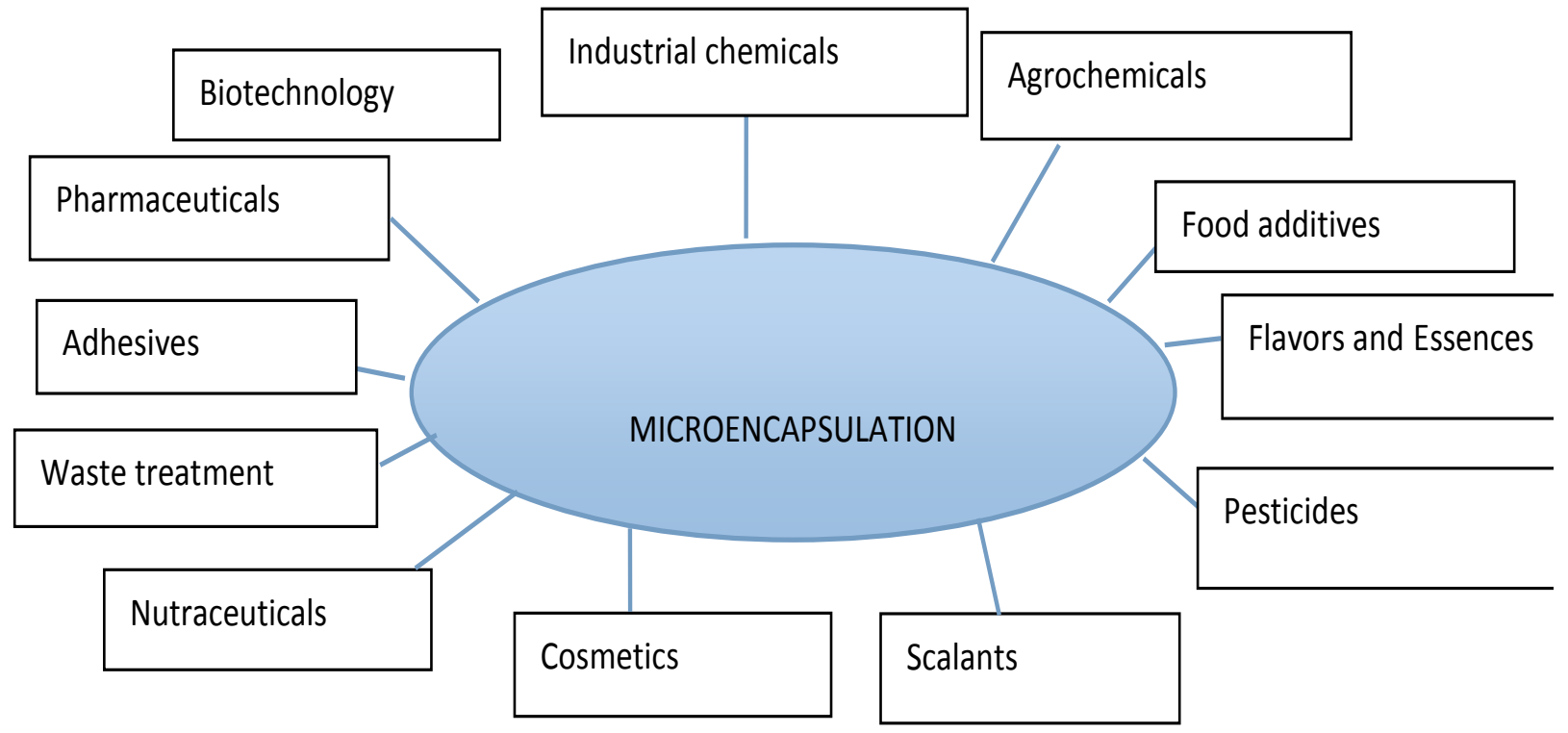

Figure 3: Schematic diagram for microencapsulation applications 


\section{Chemical Engineering Research Bulletin 19(2017) 50-56}

\section{Conclusion}

Plant extract are natural products which contains various useful volatile molecules that have been used for various application in pharmaceutical, cosmetic, agricultural, and food industries. Despite their various applications, plant extract very sensitive to environmental factor and chemically unstable. So, that, encapsulation have been emerged basically to enhance plant extract stability. Microencapsulation become an important tool to produce high quality of oil based product and health beneficial products in various field in order to enhance their chemical constituent, thermal stability, physicochemical properties, shelf-life, to protect and target the delivery of bioactive ingredients. Spray drying and coacervation are the popular techniques for the encapsulation of oils. Microencapsulated oils are being used for safe product and positive impact on the consumer health. However, the development and further research still needed to identify and develop the effective and new wall material and also to optimize the existing methods of encapsulation of microencapsulation process and their applications.

\section{References}

1. A. Torey, S. Sreenivasan, Y. L. Lachimanan, S. Sivaramakrishnan and R. Surash, "Antioxidant activity and total phenolic content of methanol extracts of Ixora coccinea". Pharmaceutical biology, 48(10), pp.1119-1123, 2010.

2. J. W. Fahey, "Moringa oleifera: A Review of the Medical Evidence for Its Nutritional, Therapeutic, and Prophylactic Properties. Part 1". Trees for life Journal, pp.1-15, 2005.

3. R. Singh and J.W. Lillard, "Nanoparticle-based targeted drug delivery" Experimental and molecular pathology, 86(3), pp.215-23, 2009.

4. C. B.Wandrey and A. Harding, "Materials for encapsulation", 2010.

5. V. Nedovic, "An overview of encapsulation technologies for food applications". Procedia Food Science, 1, pp.1806-1815, 2011.

6. A. M. Bakry, A. Shabbar, A. Barkat, M. Hamid, Y. A. Mohamed, M. Ahmed and L. Li "Microencapsulation of oils: a comprehensive review of benefits, techniques, and applications". Comprehensive Reviews in Food Science and Food Safety 15.1 (2016).

7. K. G. H. DesaiandH.Jin Park,"Recent Developments in Microencapsulation of Food Ingredients", 2005.

8. C. Thies, "Microencapsulation", Available at: http://dx.doi.org/10.1002/0471238961.130903182 0080905.a01.pub2\nhttp://en.wikipedia.org/wiki/ Micro-encapsulation, 2005.
9. A.Muninand Edwards-Lévy, F., "Encapsulation of natural polyphenolic compounds; a review". Pharmaceutics, 3(4), pp.793-829, 2010.

10. B. F. Gibbs, K. Selim, A.Inteaz,N. M. Catherine, "Encapsulation in the food industry: a review". International journal of food sciences and nutrition, 50(3), pp.213-224, 1999.

11. I. J. Joye and J. M. David "Biopolymer-based nanoparticles and microparticles: Fabrication, characterization, and application". Current Opinion in Colloid and Interface Science, 19(5), pp.417-427, 2014.

12. H. C. F. Carneiro, V. T. Renata, R. F. G. Carlos and D. H. Miriam, "Encapsulation efficiency and oxidative stability of flaxseed oil microencapsulated by spray drying using different combinations of wall materials". Journal of Food Engineering, 115, pp.443-451. Available at: http://dx.doi.org/10.1016/j.jfoodeng.2012.03.033, 2013.

13. K. N. Chen, J. C. Ming, J. R. Liu, C. W. Linand H. Y. Chiu, "Optimization of incorporated prebiotics as coating materials for probiotic microencapsulation". Journal of food science, 70(5), pp.M260-M266. Available at: http://onlinelibrary.wiley.com/doi/10.1111/j.13652621.2005.tb09981.x/abstract, 2005.

14. S. M. Jafari, A. Elham,H. Yinghe and B. Bhesh, "Encapsulation efficiency of food flavours and oils during spray drying”. Drying Technology, 26(7), pp.816-835, 2008.

15. F. Shahidiand X. Q. Han,"Encapsulation of food ingredients". Critical reviews in food science and nutrition, 33(6), pp.501-547, 1993.

16. Calvo, Patricia, Teresa Hernández, Mercedes Lozano, and David González-Gómez, "Microencapsulation of extra-virgin olive oil by spray-drying: Influence of wall material and olive quality". European Journal of Lipid Science and Technology, 112, pp.852-858, 2010.

17. J. Charve, and A. R. Gary,"Encapsulation performance of proteins and traditional materials for spray dried flavors". Journal of Agricultural and Food Chemistry, 57(6), pp.2486-2492, 2009.

18. A. Gharsallaoui, R. Gaelle,C. Odile, V. Andrée and S. Rémi "Applications of spray-drying in microencapsulation of food ingredients: An overview". Food Research International, 40(9), pp.1107-1121, 2007.

19. Z. Fang and B. Bhesh "Encapsulation of polyphenols - A review" Trends in Food Science and Technology, 21(10), pp.510-523. Available at: http://dx.doi.org/10.1016/j.tifs.2010.08.003, 2010.

20. D. A. LeClair, D. C. Emily,X. Zhou and R. T. Michael, "Microencapsulation by Spray Dryer". Drying Technology, 16(6), pp.1195-1236. 


\section{Chemical Engineering Research Bulletin 19(2017) 50-56}

Available

at:

http://dx.doi.org/10.1080/07373939808917460, 1998.

21. M. V. Bule, R. S. Rekha and F. K. John "Microencapsulation of ubiquinone-10 in carbohydrate matrices for improved stability. Carbohydrate Polymers", 82(4), pp.1290-1296. Available at: http://dx.doi.org/10.1016/j.carbpol.2010.07.012, 2010.

22. S. A. Hogan, F M. Brian, E. D. O’Riordan, and M. O'Sullivan, "Emulsification and microencapsulation properties of sodium casein ate or carbohydrate blends". International Dairy Journal, 11(3), pp.137-144, 2001.

23. K. E.Constanza, L. W. Brittany,P. D.Jack,H. S.Timothy and L. D.Lisa "Value-added processing of peanut skins: Antioxidant capacity, total phenolics, and procyanidin content of spray-dried extracts". Journal of Agricultural and Food Chemistry, 60(43), pp.10776-10783, 2012.

24. L. Zhang, M.Dehua and D. Yanshan,"Procyanidins: extraction and microencapsulation". Journal of the Science of Food and Agriculture, 87(12), pp.2192-2197. Available at: http://doi.wiley.com/10.1002/jsfa.2899, 2007.

25. U. Topal, S. Mitsuru, G. Motonobu, and O. Semih, "Chemical compositions and antioxidant properties of essential oils from nine species of Turkish plants obtained by supercritical carbon dioxide extraction and steam distillation". International journal of food sciences and nutrition, 59(7-8), pp.619-634, 2008.

26. L. S. Il'Ichev, D. G. Williamsand L. J. Gut,"Sprayable microencapsulated sex pheromone formulation for mating disruption of oriental fruit moth (Lepidoptera: Tortricidae) in Australian peach and pear orchards". Journal of economic entomology, 99(6), pp.2048-2054, 2006.

27. Z. L. Chen, Y. L. Fang and Z. N. Zhang, "Synthesis and assessment of attractiveness and mating disruption efficacy of sex pheromone microcapsules for the diamondback moth, Plutella xylostella (L.)". Chinese Science Bulletin, 52(10), pp.1365-1371, 2007.

28. R. Langer, "New methods of drug delivery. Science, 249(4976), pp.1527-1533. Available at: http://eutils.ncbi.nlm.nih.gov/entrez/eutils/elink.fc gi? dbfrom $=$ pubmed $\&$ id $=2218494 \&$ retmode $=$ ref $\&$ cmd=prlinks $\backslash$ npapers3://publication/uuid/E082339 A-681A-4647-A921-6394611BF634,1990.
29. U. R. Pothakamury and G. V. Barbosa-Cánovas, "Fundamental aspects of controlled release in foods". Trends in Food Science \& Technology, 6(12), pp.397-406, 1995.

30. P. Morand-Fehr, "Recent developments in goat nutrition and application: A review". Small Ruminant Research, 60(1-2), pp.25-43.

31. L. Galego, A. Valentim, G. Vera, C. Costa, M. Isabel, M. Fabíola and M. Graça, "Antioxidant activity of the essential oils of Thymbra capitata, Origanum vulgare, Thymus mastichina, and Calamintha baetica". Proceedings of the International Symposium on Plants as Food and Medicine The Utilization and Development of Horticultural Plants for Human Health, (765), pp.0-325, 2008.

32. F. de Barros, V. Regiane, V. B. Soraia, and A. B. Diego, "Gum arabic/starch/maltodextrin/inulin as wall materials on the microencapsulation of rosemary essential oil". Carbohydrate Polymers, 101, pp.524-532. Available at: http://dx.doi.org/10.1016/j.carbpol.2013.09.083, 2014.

33. C. Dima, C. Mihaela, A. Petru, and D. Stefan, "Microencapsulation of essential oil of pimento [Pimenta dioica (L) Merr.] by chitosan/kcarrageenan complex coacervation method". Innovative Food Science and Emerging Technologies, 22, pp.203-211. Available at: http://dx.doi.org/10.1016/j.ifset.2013.12.020, 2014.

34. A.López, S. Castro, M. J. Andina, X. Ures, B. Munguía, J. M. Llabot, H. Elder, E. Dellacassa, S. Palma and L. Domínguez, "Insecticidal activity of microencapsulated Schinus molle essential oil". Industrial Crops and Products, 53, pp.209-216, 2014.

35. C.Cwikla, K. Schmidt, A. Matthias, K. M. Bone, R. Lehmann and E. Tiralongo, "Investigations into the antibacterial activities of phytotherapeutics against Helicobacter pylori and Campylobacter jejuni. Phytotherapy”, 24(5), pp.649-656. Available

http://www3.interscience.wiley.com/journal/12252 2173/abstract, 2010.

36. A. K. Pandey, P. Singh, and N. N. Tripathi, "Chemistry and bioactivities of essential oils of some Ocimum species: an overview". Asian Pacific Journal of Tropical Biomedicine, 4(9), pp.682-694. Available at: http://www.apjtb.com/zz/20149/4.pdf, 2014.

\section{Available online at http://www.banglajol.info/index.php/CERB}

Publisher: Department of Chemical Engineering, Bangladesh University of Engineering and Technology (BUET). Review \&Publication: A submitted original manuscript is taken into review only if the uniqueness is found to be more than $85 \%$ in plag-scanning and selected for publication by the complete acceptance from at least two reviewers out of three. Home Page: http://www.banglajol.info/index.php/CERB. Indexed by Chemical Abstract Service (CAS), CEABA-VtB, Google Scholar, Scopus and DOAJ. 